\title{
THE HISTOCHEMICAL AND BIOCHEMICAL EFFECTS OF COCONUTMILK IN WISTAR RATS WITH ETHANOL-INDUCED GASTRIC ULCER
}

\author{
Omojola A. Tolulope ${ }^{a *}$, Ofusori A. David a, Edward S. Sylvester ${ }^{b, c}$, Umeaku Ugochukwua, \\ a Department of Anatomy and Cell Biology, Faculty of Basic Medical Sciences, Obafemi Awolowo University, Ile- \\ Ife, Osun State, Nigeria. \\ b Department of Physiological Sciences, Faculty of Basic Medical Sciences, Obafemi Awolowo University, Ile-Ife, \\ Osun State, Nigeria. \\ c Department of Pediatrics, Obafemi Awolowo University Teaching Hospital Complex, Ile-Ife, Osun State, Nigeria. \\ d Department of Morbid Anatomy, Obafemi Awolowo University Teaching Hospital Complex, Ile-Ife, Osun State, \\ Nigeria.
}

*Correspondence to Omojola TA Department of Anatomy and Cell Biology, Faculty of Basic Medical Sciences, Obafemi Awolowo University, Ile-Ife, Osun State, Nigeria. Email address tfolayemi@gmail.com.

\begin{abstract}
This study aimed at investigating the histochemical and biochemical effects of coconut milk in Wistar rats' model of ethanol-induced gastric ulcer with a view to evaluating the antiulcerogenic potential of coconut milk in the management of gastric ulcer. Thirty male Wistar rats weighing between $150-180 \mathrm{~g}$ were recruited for the study and divided into six groups of 5 rats each. All the groups were fasted for 24-hours after which group-1 received single oral administration of normal saline at $5 \mathrm{ml} / \mathrm{kg}$, while groups 2-6 received equivalent amount of ethanol. Twenty-four hours later, Groups-3, 4, 5 received oral graded doses of coconut milk at 30,50,70 mg/kg respectively while group 6 received omeprazole administration at $10 \mathrm{mg} / \mathrm{kg}$ every 12-hours for a period of 21 days. The ulcer index as well as Prostalglandin- $E_{2}$ and Nitric Oxide concentrations was significantly $(p<0.05$ ) lowered following treatment with omeprazole and coconut milk, when compared with the ethanol group. Coconut milk administration also attenuated the ethanol-induced histochemical distortions of the gastric pylorus. This study concluded that coconut milk administration ameliorated ethanol-induced gastric ulcer and serves as a potential choice in the treatment of the condition.
\end{abstract}

Key Words: Gastric ulcer, Ethanol, Coconut Milk, Omeprazole, Histochemical, Biochemical.

\section{INTRODUCTION}

Gastric ulcer is a defect or break in the mucosal lining of the stomach and it is a form of peptic ulcer disease. The secretion of acid and pepsin by the stomach is controlled by neuro-hormonal mechanism to prevent gastric hyperacidity and ulceration (Bandyopadhyay et al., 2001). Gastric ulceration occurs when the effects of some aggressive factors become more pronounced and overwhelmed the mucosa protective mechanism (Jainu et al., 2006). These aggressive factors include alcohol, Helicobacter py/ori infection, non- steroidal antiinflammatory (NSAIDs), cigarette smoke, genetic factors and various foods (Graham, 2003). As of today, there is high incidence of gastric ulcer in Nigeria (Ijarotimi et al., 2017). Globally, alcohol has been useful for centuries in social, medical, cultural and religious settings. It has been estimated that about 2billion people consume alcoholic beverages worldwide; however, 76.3million people have diagnosable alcohol related disorders (WHO, 2010). There is also an increasing trend in the use of alcohol in Nigeria (Dumbili, 2013); its consumption continues to experience strong growth as a result of the aggressive marketing activities of leading players, and its acceptability in many social functions. In Nigeria, alcohol is a major factor that causes road accidents and injuries (Lasebikan and Baiyewu, 2009) and is 
also associated with physical health problems (Gureje and Lasebikan, 2006) which is similar to the situation in Western World. In the last few years, local brew with different alcohol concentrations have emerged as another public health issue (Lasebikan and Ayinde, 2013). Alcohol leads to the impairment of the integrity of gastric mucosal barrier, contributing to acid reflux into the subluminal layer of the mucosa and submucosal (Oh et al., 2005). Absorption of alcohol into the blood stream occurs throughout the gastrointestinal tract and its direct contact with the mucosal can lead to marked damage resulting into ulcer (Bode and Bode, 1997). Alcohol also causes gross mucosal lesion and hemorrhagic bands (Mozafar and Hossein, 2006).

In view of these, scientists have looked into ways in which gastric ulcer can be treated using natural herbs (Nneli and Woyike, 2008; Alebiosu, 2012). Coconut milk (CM) is got from coconut (Cocosnucifera) which belongs to the Araceceae family. Coconut milk is the liquid obtained through manual or mechanical force of coconut meat (Naratarukae et al., 2010).
Coconut milk contains essentially high amount of protein, amino acids, water, sugar, fats, vitamins and minerals (Effiong, 2003). The milk contains significant amounts of fat, but unlike other nuts, it provides fat that is mainly in the form of medium chain saturated fatty acids (MCFAs) that is abundant in mother's milk in particular, lauric acid (Baldioli et al., 1996); this is converted in the body into a highly beneficial compound called monolaurin, an antiviral and antibacterial that destroys a wide variety of disease-causing organisms. According to the National Center for Biotechnology Information, lauric acid has many germs fighting, antifungal and antiviral properties that are very effective at ridding the body of viruses, bacteria and countless illnesses (Baldioli et al., 1996). It has been reported that $\mathrm{CM}$ has a greater protection in indomethacin induced ulceration when compared with coconut water (Nneli and Woyike, 2008). A thorough search into the literature shows dearth of information on the biochemical and histochemical effects of ethanol induced gastric ulcer, hence this study.

\section{MATERIALS AND METHODS}

Thirty male wistar rats, weighing between 150 and $180 \mathrm{~g}$ were used for the study. The rats were randomly assigned into six groups. The animals were housed in plastic cages and acclimatized for two weeks before the commencement of the research and they were kept at room temperature, fed with standard animal diet and allowed free access to clean water and food. Ethical approval for this work was obtained from the Health Research Ethics Committee (HREC), Institute of Public Health, Obafemi Awolowo University, Ile-Ife, Nigeria, IPHOAU/12/587.

Ethanol (99.75\%) a product of BDH Chemicals Limited, Poole England was used for the induction. Omeprazole was purchased from a government approved pharmaceutical company in Ile-Ife. Prostaglandin $E_{2}$ was procured from Elabscience laboratory, China. Nitric oxide was manually assayed for in the Biochemistry department of Obafemi Awolowo University, Ile-Ife.

The coconut fruit was authenticated by $a$ taxonomist in Botany Department, Obafemi Awolowo University Ile-Ife with a voucher number of (IFE- 17488). The coconuts were cracked; fresh nuts were removed and chopped into tiny bits with the aid of knife. The chopped nuts were grated with fruit extractor (Original Millennium NAKAI Blender, ST-003 SPECIAL, JAPAN) and filtered with a sieve, thereafter the filtrate was processed into powder using a lyophilizing machine (CHRiST, BETA 1-8, Germany), which was stored at $4^{\circ} \mathrm{C}$ before use.

At the beginning of the experiment, all the rats were fasted for 24 hours. Administrations of ethanol, graded doses of coconut milk and omeprazole were given through oral route by oral cannula. Gastric lesion was induced in groups 2, 3, 4, 5 and 6 rats by a single oral 
administration of $5 \mathrm{ml} / \mathrm{kg}$ of ethanol following overnight fasting. At the same time, rats in group 1 were given equivalent volume of normal saline. Twenty-four hours later, rats in groups 3, 4 and 5 were started on CM dissolved in normal saline at graded dosages of 30, 50 and $70 \mathrm{mg} / \mathrm{kg} 12$ hourly respectively for a period of 21 days. Group 6 rats received Omeprazole $10 \mathrm{mg} / \mathrm{kg} 12$ hourly, dissolved in normal saline, for a period of 21 days. Rats in groups 1 and 2 received equivalent volumes of same normal saline used in dissolving the CM and omeprazole 12 hourly for the same period of time.

Twenty- four hours after the last administration of CM and omeprazole, all the rats were fasted and sacrificed under slight chloroform anesthesia. The stomachs of the animals were resected, open along the greater curvature; these were washed in normal saline and Pinned to a dissecting board for gross photography using high resolution camera (TECNO C8 with resolution of 13.0) at a fixed distance from the tissue.

Image captured were imported into Image-J software for measurement and determination of ulcer index. Ulcer index was calculated by the method of Ganguly. (Ganguly,1969). UI=10/x, where $x=$ Total mucosal surface/ Total ulcerated area. Image analysis and processing for Java (image J), sponsored by the National Institute of Health (USA), and was used in the analysis and quantification of DNA from Feulgen stain.

Feulgen staining technique was carried out to demonstrate the presence of DNA as described by Bancroft and Gamble (Bancroft and Gamble, 2002) following fixation in $10 \%$ formol saline, embedded using paraffin wax and sectioned at $5 \mu \mathrm{m}$ thickness using a rotary microtome.

The intensity of feulgen staining to determine the presence of DNA was performed by measuring the mean gray value of pixels. The software quantifies staining intensity by measuring the pixel value of each pixel in gray scale images. Values of intensity for each of the photomicrographs per group were generated which was then run through a statistical package (GraphPad prism) to get the mean and standard error of mean and to be able to compare the intensity across the group.

Table 1: Experimental design

\begin{tabular}{|l|l|l|}
\hline Groups & After $\mathbf{2 4}$ hours fasting & $\mathbf{2 1}$ days oral administration \\
\hline Group 1 & NS $(1 \mathrm{~mL} / \mathrm{kg})$ p.o. & NS $(1 \mathrm{~mL} / \mathrm{kg}) 12$ hourly* \\
\hline Group 2 & Ethanol $(5 \mathrm{~mL} / \mathrm{kg})$ p.o. & NS $(1 \mathrm{~mL} / \mathrm{kg}) 12$ hourly* \\
\hline Group 3 & Ethanol $(5 \mathrm{~mL} / \mathrm{kg})$ p.o. & $\mathrm{CM}(30 \mathrm{mg} / \mathrm{kg}) 12$ hourly* \\
\hline Group 4 & Ethanol $(5 \mathrm{~mL} / \mathrm{kg})$ p.o. & $\mathrm{CM}(50 \mathrm{mg} / \mathrm{kg}) 12$ hourly* \\
\hline Group 5 & Ethanol $(5 \mathrm{~mL} / \mathrm{kg})$ p.o. & $\mathrm{CM}(70 \mathrm{mg} / \mathrm{kg}) 12$ hourly* \\
\hline Group 6 & Ethanol $(5 \mathrm{~mL} / \mathrm{kg})$ p.o. & $\mathrm{OZ}(10 \mathrm{mg} / \mathrm{kg}) 12$ hourly* \\
\hline
\end{tabular}

NS = normal saline; $\mathrm{CM}=$ coconut milk; $\mathrm{OZ}=$ omeprazole; p.o. = par oral; $*=$ point at which the rats were sacrificed. 
After the stomach has been harvested, opened along the greater curvature and washed in normal saline, it was placed on ice and the mucosa was gently scraped into a specimen bottle and kept in a freezer at $-20^{\circ} \mathrm{C}$. Nitric oxide levels in the gastric mucosa were measured as total nitrite and nitrate level with the use of Greiss reagent by the method of Moshage and coworkers (Moshage et al., 1995).Tissue concentration of Prostaglandin $E_{2}$ was determined by using prostaglandin $\mathrm{E}_{2}$ ELISA Assay kit (Elabscience laboratory, China). The manufacturer's manual was strictly followed.
Comprehensive chemical tests to identify the secondary metabolites present in the Cocosnucifera L. Such as alkaloids, flavonoids, tannins, cardiac glycosides, terpenoids, steroids/phytosterols, saponins, xanthoproteins, phlobatanins and anthraquinones were carried out as described by Oyedapo and coworkers (Oyedapo et al., 1999).

Data were evaluated by One Way Analysis of Variance (ANOVA) using SPSS (version 20) with Duncan Multiple Range Test option and p-values < 0.05 were considered significant.

\section{RESULTS}

Ethanol induced ulceration and hemorrhagic lesions in the stomach as shown in figure1. All the animals in the ethanol-induced groups developed gastric ulceration macroscopically; however gastric lesions were most severe in group $2(40 \%)$ with presence of numerous ulcers in the mucosae. Treatment with $\mathrm{CM}$ at graded dosage with Omeprazole resulted in less ulceration, as evidenced in the percentage ulcer score shown in table 3 . The percentage ulcer score in group 2 was higher compared with the treated groups 3, 4, 5 and $6(20,12,8$, and $6 \%$ respectively). No lesion was found in the normal control group as shown in table 3 . There was a significant increase $(p<0.001, F=$ 24.95) in ulcer index of group $2(0.30 \pm 0.06)$ when compared with groups $3,4,5$ and $6(0.05 \pm 0.02,0.07 \pm 0.04,0.08 \pm 0.01,0.04 \pm 0.01$ respectively). There was a significant decrease $(p<0.001)$ in ulcer index in group 3, 4 and 5 in a dose dependent fashion among the CM treated groups. Comparing Group 6 with groups 3, 4and 5, there was no significant difference $(p<0.001$ ) in groups 4 and 5 but there was a significant increase $(p<0.001)$ in group 3 as shown in figure 2 . The gastric ulcer curative ratio (\%) increased in a dose dependent fashion (group $3=73.33$, group $4=76.67$, group $5=83.33$, and group $6=86.67$ ) as shown in table 3.
Control group showed a well arranged and high density of DNA within the nucleus as shown in Fig.4. In the group treated with ethanol only, there was scanty and displacement in the arrangement of the DNA within the nucleus as evident in Fig.3. While in the treated groups, observable numerous and better arranged DNA within the nucleus was noticed. The staining intensity (\%) in figure 4.6 showed a significant decrease $(p<0.001, F=43.12)$ in group 2 $(10.64 \pm 1.44)$ when compared with groups 3 , 4,5 and 6 (17.22 \pm 2.07, $33.22 \pm 1.85$, $35.35 \pm 1.95$ and $42.97 \pm 2.14$ respectively). There was a significant increase $(p=0.00)$ in groups 3, 4 and 5 in a dose dependent fashion when compared with one another. There was a significant increase $(p=0.00)$ in group 6 treated with $\mathrm{OZ}$ when compared with groups 3,4 , and 5. Group 1 showed a significant increase $(p<$ $0.001)$ when compared with other groups $(2,3$, 4, 5 and 6) as shown in Fig. 4.

There was a significant decrease $(p=0.02, F=$ 16.12 ) in the concentration of nitric oxide ( $\mu$ mole) in group 2 (2.39 \pm 0.20$)$ when compared with groups 3, 4, 5 and 6 (2.60 \pm $0.11,2.99 \pm 0.26,3.41 \pm 0.10$ and $3.54 \pm 0.10$ respectively). There was a significant increase ( $p=0.02)$ in a dose dependent manner when groups 3, 4 and 5 were compared with one another. In group 6 treated with $O Z$, the nitric oxide concentration was found to be 
significantly increase $(p=0.02)$ when compared with groups 3, 4 and 5 treated with graded dosage of $\mathrm{CM}$. The concentration of nitric oxide in groups 2, 3, 4, 5 and 6 was found to be significantly decreased when compared with group 1 (4.27 \pm 0.19$)$ as shown in Fig. 5 .

The concentration of prostaglandin $E_{2}(p g / m l)$ in group $2(139.20 \pm 50.90)$ was significantly reduced $(p<0.001, F=7.16)$ when compared with the treated groups 3, 4, 5and $6(169.06 \pm$ $69.17,144.25 \pm 32.03,223.76 \pm 81.06$ and $328.28 \pm 120.08$ respectively). Comparing the level of $\mathrm{PGE}_{2}$ concentration across the treated groups 3, 4, 5 and 6, there was no significant difference noticed $(p<0.001)$ except in group $C$. However, there was no significant difference $(p<0.001)$ when the treated groups 4 and 5 $(50 \mathrm{mg} / \mathrm{kg}$ and70 $\mathrm{mg} / \mathrm{kg}$ ) were compared with group 6 treated with $(\mathrm{OZ} 10 \mathrm{mg} / \mathrm{kg})$ except in group C $(30 \mathrm{mg} / \mathrm{kg})$. The negative control group 1 (203.56 \pm 57.68) significantly increased $(p<0.001)$ when compared to group 2 and treated groups 3, 4, 5 and 6 as shown in Fig. 6.
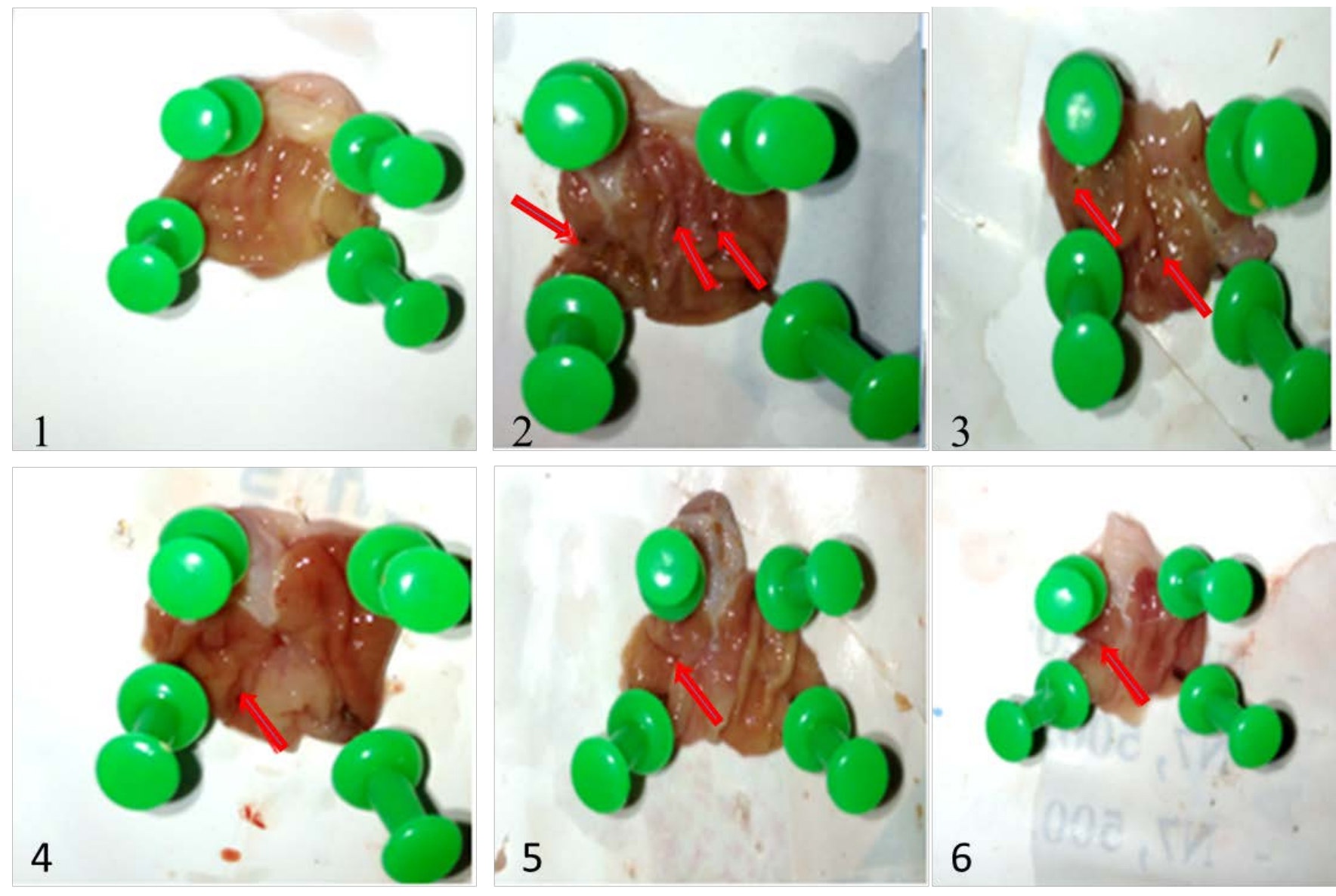

Figure 1: Macroscopic effects of coconut milk on the stomach of rats with ethanol-induced gastric ulcer. 1 (control), 2 (Ethanol only), 3 (Ethanol $+30 \mathrm{mg} / \mathrm{kg} \mathrm{CM}), 4$ (Ethanol $+50 \mathrm{mg} / \mathrm{kg} \mathrm{CM}), 5$ (Ethanol $+70 \mathrm{mg} / \mathrm{kg} \mathrm{CM}), 6$ (Ethanol $+10 \mathrm{mg} / \mathrm{kg}$ Omeprazole). Red arrow $=$ ulcer point. 
Table 2: Qualitative Summary of the Phytochemical Constituents of Coconut Milk

\begin{tabular}{|l|c|c|}
\hline \multicolumn{1}{|c|}{ Phytochemical Constituents } & Present $\{+\}$ & Absent $\{-\}$ \\
\hline Alkaloids & + & + \\
\hline \multicolumn{1}{|l|}{ Mayer's reagent } \\
$\quad \begin{array}{l}\text { Wagner's reagent } \\
\text { Dragendorf reagent } \\
\text { Picric acid }\end{array}$ & + & \\
\hline $\begin{array}{l}\text { Flavonoids } \\
\text { Cardiac glycosides }\end{array}$ & + & - \\
\hline Saponins & & - \\
\hline Steroids & + & \\
\hline Tannins & + & - \\
\hline Terpenoids & + & - \\
\hline Xanthoproteins & & - \\
\hline Phlobatanins & & \\
\hline Anthraquinone & & \\
\hline Resin & & \\
\hline
\end{tabular}

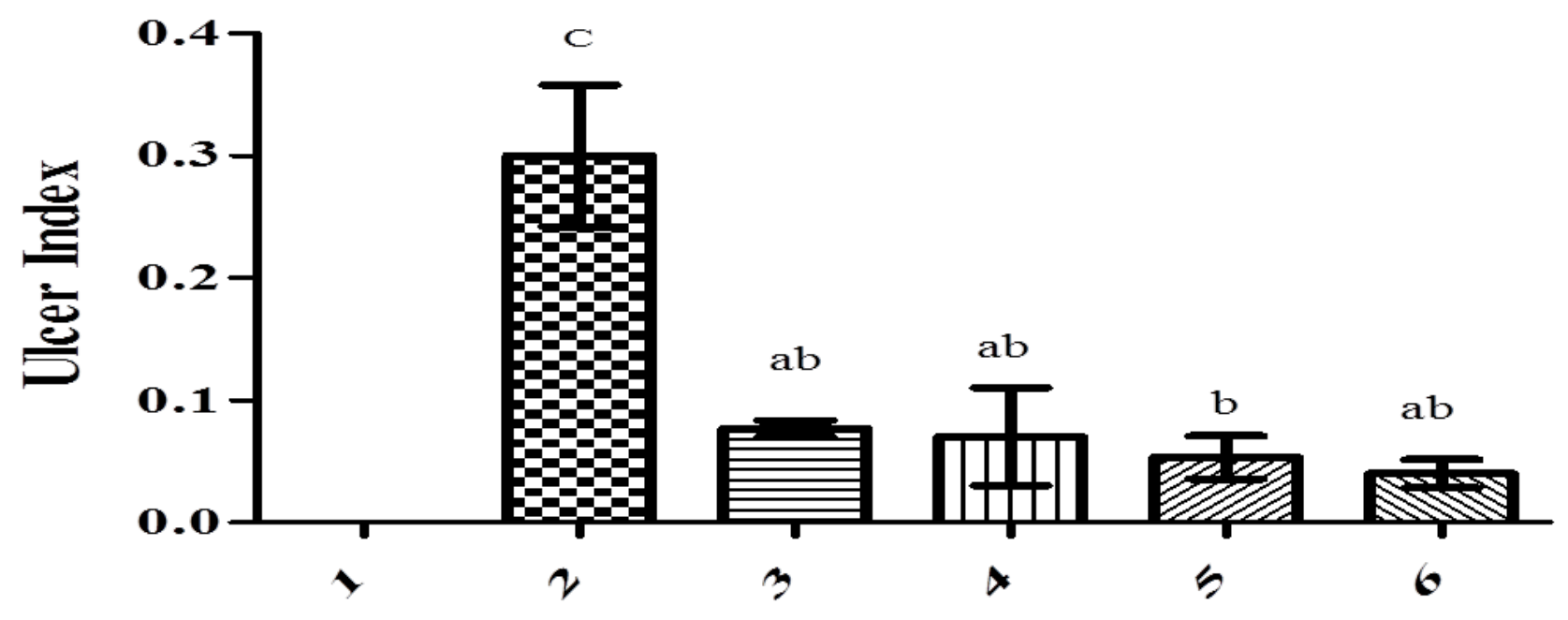

Groups

Figure 2: Ulcer index of the stomach of coconut milk-treated rats following ethanol-induced gastric ulcer. Each bar represents Mean \pm S.E.M. a, b, $c$ within column signifies that means with different letters differs significantly at $p<0.001$ while means with the same letters does not differ significantly at $p<0.001$. 
Table 3: Macroscopic Assessment on the Stomach

\begin{tabular}{|l|l|l|}
\hline & PERCENTAGE ULCER SCORE \% & CURATIVE RATIO \% \\
\hline GROUP 1 & - & - \\
\hline GROUP 2 & 40 & 0 \\
\hline GROUP 3 & 20 & 73.33 \\
\hline GROUP 4 & 12 & 76.67 \\
\hline GROUP 5 & 8 & 83.33 \\
\hline GROUP 6 & 6 & 86.67 \\
\hline
\end{tabular}
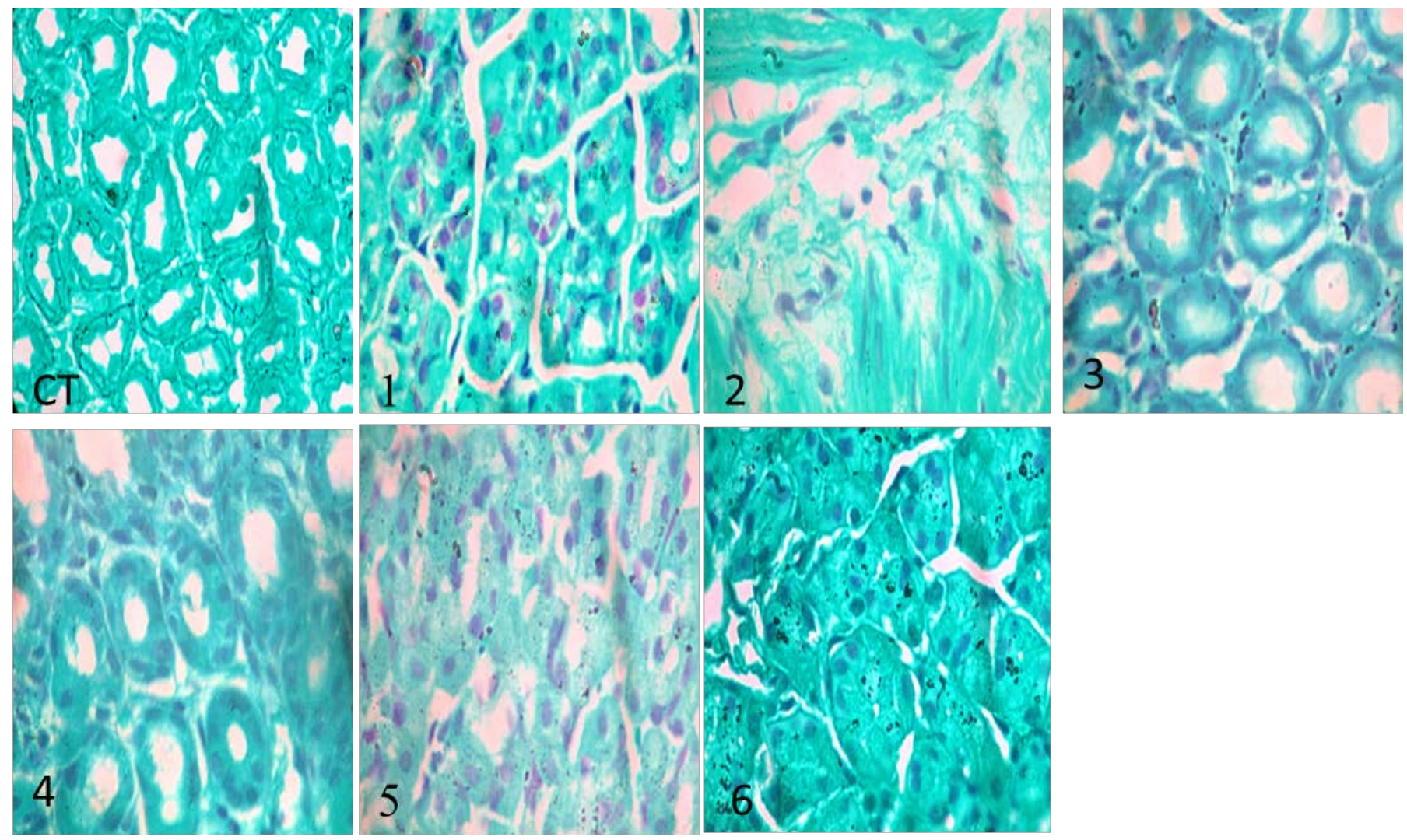

Figure 3: Photomicrographs of pylorus of the stomach of coconut milk-treated rats following ethanol-induced gastric ulcer. 1 (control), 2 (Ethanol only), 3 (Ethanol $+30 \mathrm{mg} / \mathrm{kg} \mathrm{CM}), 4$ (Ethanol $+50 \mathrm{mg} / \mathrm{kg} \mathrm{CM}), 5$ (Ethanol + 70mg/kg CM), and 6 (Ethanol $+10 \mathrm{mg} / \mathrm{kg}$ Omeprazole). Feulgen x100. DNA stains purplish red. 


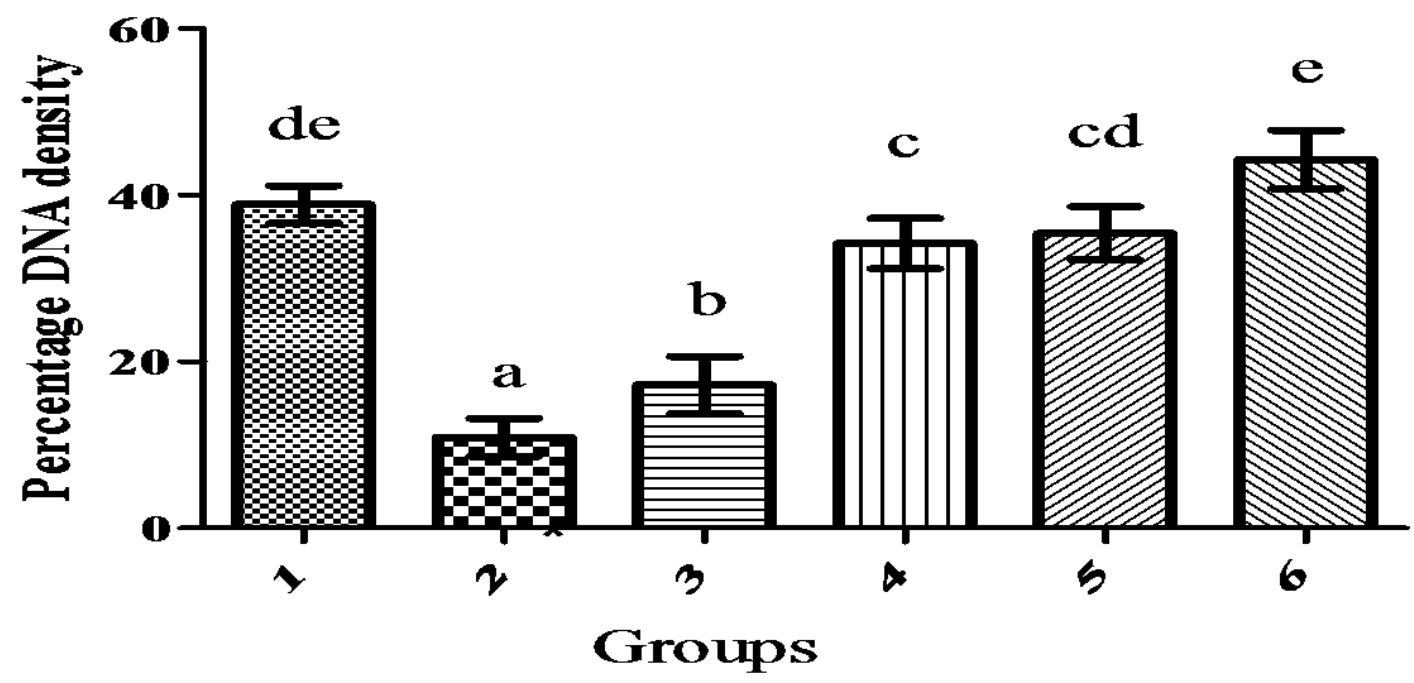

Figure 4: Percentage DNA density of the stomach of coconut milk-treated rats following ethanol-induced gastric ulcer. Each bar represents Mean \pm S.E.M. for quantification of Feulgen staining intensity. a, b, c, cd, de, e within the column signifies that means with different letters differs significantly at $p<0.001$.

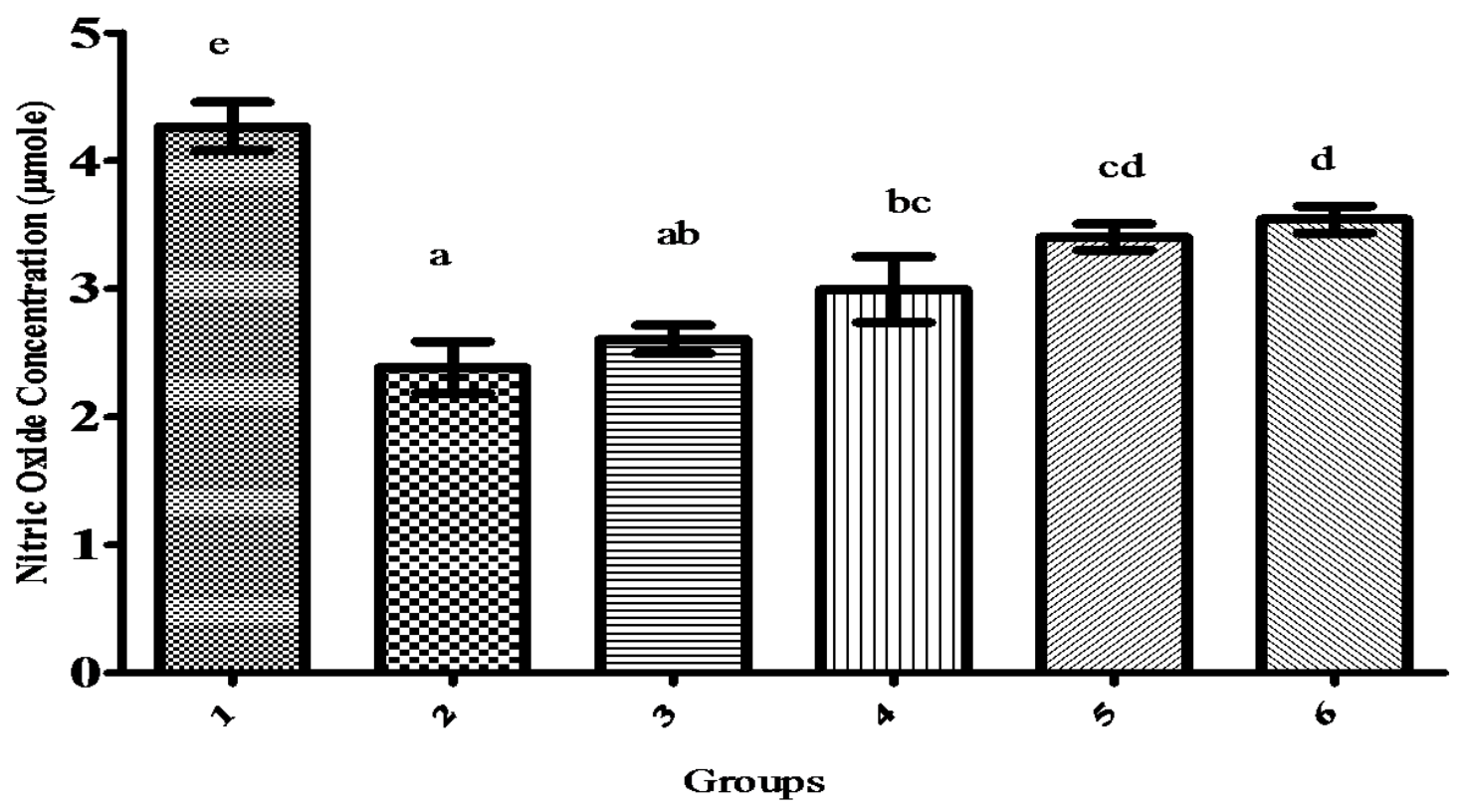

Figure 5: Nitric oxide concentration in the stomach of coconut milk-treated rats following ethanol-induced gastric ulcer. Each bar represents Mean \pm S.E.M. for Nitric Oxide Concentration in each group $a$, ab, bc, cd, d, e within column signifies that means with different letters differs significantly at $p<0.001$ while means with the same letters does not differ significantly at $p<0.001$. 


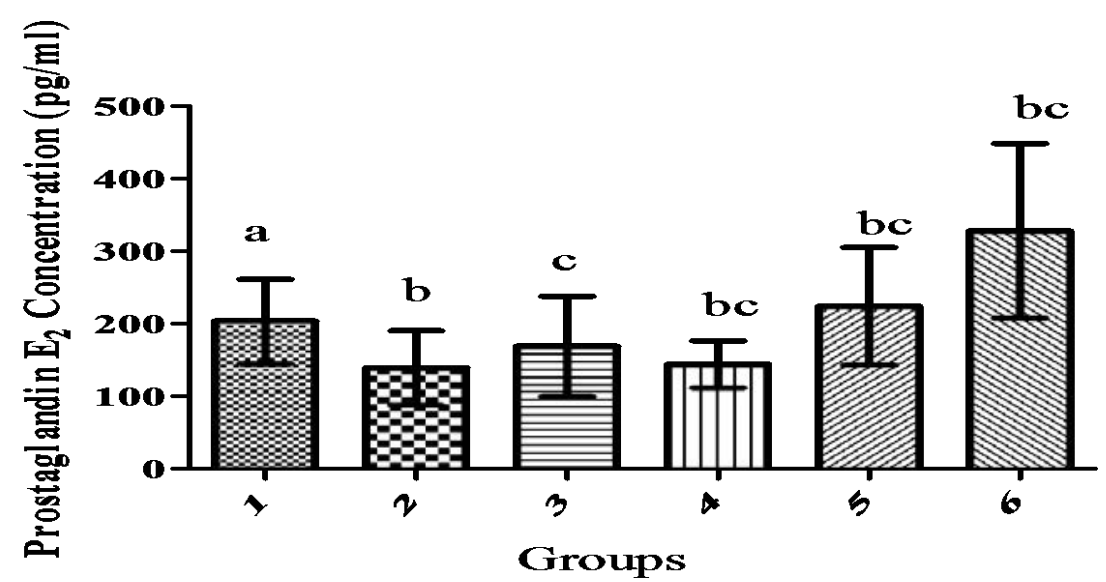

Figure 6: Prostaglandin $E_{2}$ Concentration in the stomach of coconut milk-treated rats following ethanolinduced gastric ulcer. Each bar represents Mean \pm S.E.M. in each group. $a, b, b c$, c within column signifies that means with different letters differs significantly at $p<0.001$ while means with the same letters does not differ significantly at $p<$ 0.001 .

\section{DISCUSSION}

In this study, single dose $(5 \mathrm{ml} / \mathrm{kg})$ of ethanol administration caused gastric ulceration. The ulceration resulted from the noxious effect of ethanol on the mucosa leading to loss of epithelium. Gastric ulcers were demonstrated macroscopically and supported by histomorphometric measurements in this study.

An increase in ulcer score and ulcer index in groups induced with ulcer via administration of ethanol in this study is indicative of the degree of ulceration. This is in line with Amol coworkers who worked on the anti-ulcer effect of amlodipine in gastric ulcer model in rat (Amol et al., 2012). Also, Edward and coworkers affirmed that the ulcer index of the ethanol only group increased while the treated group decreased (Edward et al., 2005). In this study, it was found that there was a significant increase in the ulcer index in the rats treated with ethanol only when compared with the treated groups; whereas in the groups treated with coconut milk and omeprazole there was a significant decrease when compared to the ethanol only group. This result corroborates the findings of Rydning and coworkers who confirmed that alcohol, aspirin and NSAIDs can aggravate healing of peptic ulcer (Rydning et al., 1982). Ethanol, NSAIDs and nicotine are considered as major causative factors in the development of acute mucosal damage and gastric ulcer (Brzozowski et al., 2006; ChavezPina and Tapia Alvarez, 2010). Decrease in ulcer index in the groups treated with coconut milk may be due to the presence of tannin, sapponin and flavonoid present in the coconut milk as evident in the phytochemical screening of this study. Tannins, sapponin and flavonoids have been reported to have anti-ulcer properties (Alkofahi and Atta, 1999).

Feulgen is a histochemical stain specific for DNA. From the present study, there was a significant decrease in DNA density in group B which is indicative of cellular degeneration. This is in corroboration with Castelain and coworkers who worked on cell population kinetic and ploidy rates during hepatocarcinogenesis (Castelain et al., 1989). In the coconut milk and omeprazole groups, the DNA density significantly increased in a dose dependent manner as shown in the photomicrographs. This may be the result of wound healing process taking place as a result of the regenerative potential of coconut milk. Phytochemical constituents such as flavonoid; 
saponin and tannin have been reported to enhance the wound healing process (Udegbunam et al., 2015). These constituents promote wound healing process by increasing the DNA synthesis (Majumdar et al., 2007). Also, flavonoids influence cell cycle and DNA metabolism (Nakamura and Miyoshi, 2010).

This present study showed that there was a significant decrease of gastric mucosa nitric oxide concentration in rats treated with ethanol only. There was a significant increase in a dose dependent fashion in the level of nitric oxide concentration in the treated groups. This can be attributed to the anti-oxidant properties present in the coconut milk (Alyaqoubi et al., 2015). This increment in nitric oxide concentration may be one of the potential targets by which coconut milk protect the mucosal integrity. This involves the activation of nitric oxide synthetase by phosphorylation which eventually leads to the bioavailability of NO as documented by (Taye and Saad, 2009).

Prostaglandin $E_{2}$ is one of the major prostaglandins produced by human and rodent gastric mucosa according to (Peskaar et al.,
1980). Prostaglandins has been known to function in the protection of the stomach from gastric injury by stimulating the secretion of bicarbonate and mucus, mucosa blood flow and regulating mucosa turnover and repair (HirumaLima et al., 2006; Okokon et al., 2011). The significant increase of prostaglandin $E_{2}$ in the rats treated with $\mathrm{CM}$ and $\mathrm{OZ}$ when compared with ethanol only is in line with the study of (Mizuno et al., 1997) who reported that ethanol suppresses gastric prostaglandin synthesis. According to (Bode et al., 1996), decrease formation of prostaglandins is implicated in alcohol induced gastric mucosal damage. Prostaglandin $E_{2}$ is essential for homeostatic function including protection of gastro intestinal mucosa from damage by maintaining blood flow and increasing mucosal secretion of mucous (Voutilainen et al., 2001).

In conclusion, coconut milk potentiates antiulcerogenic effects in Wistar rats with ethanol-induced gastric ulcer, with the highest dose $(70 \mathrm{mg} / \mathrm{kg})$ having the most therapeutic effect. Therefore, coconut milk represents a therapeutic alternative in the treatment or management of gastric ulcer.

Acknowledgement: The authors wish to acknowledge Mr T.S. Adelodun of the Department of Anatomy and Cell Biology for his kind support and technical assistance.

Conflict of interest: Nil.

\section{REFERENCES}

1. Alebiosu CO, Ugwah OM, Ugwah-Oguejiofor CJ, Njan AA. 2012. Ethno botanical studies of medicinal plants used in the management of peptic ulcer disease in Sokoto State, North Western Nigeria, Int. Res. J. Pharm. Pharmacol. 2: 225-230.

2. Alkofahi A and Atta AH. 1999. Pharmacological screening of anti-ulcerogenic effects of some Jordanian medicinal plants in rats, J. Ethnopharm. 67:341-345.

3. Alyaqoubi S, Abdullah A, Samudi M, Abdullah N, Addai ZR, Musa KH. 2015. J. Chem. Pharm. Res. 7: 967973.

4. Manjari NP, Malli GA, Sudhir SN, Sanket P, Raut B. 2012. Evaluation of anti-Ulcer effect of amlodipine in gastric ulcer models in rats. Ind. J. Pharmacol. 44: 387-389.

5. Bancroft JD, Gamble M. 2002. Theory and practice of histology techniques. Elsevier Health Sciences.5 ${ }^{\text {th }}$ edition, Edinburgh: Churchill Livingstone. pp 172-620.

6. Bandyopadhyay D, Biswas K, Bhattacharyya M, Reiter RJ, Banerjee RK. 2001. Gastric toxicity and mucosal ulceration induced by oxygen derived reactive species, protection by melatonin. Curr. Mol. Med. 1: 501 513.

7. Bode C and Bode JC. 1997. Alcohol's role in gastrointestinal tract disorders, Alch. Health Res. World. 21:76-83. 
8. Bode C, Maute G, Bode JC. 1996. Prostaglandin E2 and prostaglandin F2 alpha biosynthesis in human gastric mucosa: Effect of chronic alcohol misuse. Gut. 39: 348-352.

9. Brzozowski T, Konturek PC, Mierzwa M, Drozdowicz D, Bielanski W, Kwiecien S, Konturek SJ, Stachura J, Pawlik WW, Hahn EG. 2006. Effect of probiotics and triple eradication therapy on the cyclooxygenase (COX)-2 expression, apoptosis, and functional gastric mucosal impairment in Helicobacter pylori infected Mongolian gerbils, Helicobacter. 11:10-20.

10. Castelain A, Deleener M, Kirsch-Volders M, Barbason H. 1989. Cell population kinetics and ploidy rate of early focal lesions during hepatocarcinogenesis in the rat. Br. Journal. Cancer. 60: 827-833.

11. Chávez-Piña AE, Tapia-Alvarez GR, Navarrete A. 2010. Inhibition of endogenous hydrogen sulfide synthesis by PAG protects against ethanol-induced gastric damage in the rat. Eur. J. Pharmacol. 630: 131-136.

12. Dumbili EW, 2013. Changing patterns of alcohol Consumption in Nigeria: An exploration of Responsible factors and consequences. J. BSA Medsoc. Group. 7: 20 - 33.

13. Edward O, Adeyemi-Salim AB, Irwin SC, Mohammed YH, Mohammed F, Abdu A. 2005. Mechanism of action of Leptin in preventing gastric ulcer, World J. Gastro. 11: 4154-4160.

14. Effiong GS. 2003. Characterization and chemical composition of coconut water and coconut milk. J. Pure Appl. Sci. 6:26-32.

15. Ganguly AK. 1969. A method for quantitative assessment of experimentally produced ulcers in stomach of rats, Experientia. 25: 1224.

16. Graham DY. 2003. Changing patterns of peptic ulcer, gastro-oesophageal reflux disease and Helicobacter pylori: a unifying hypothesis, Eur. J. Gastrol. Hepatol. 15: 571.

17. Gureje $\mathrm{OO}$ and Lasebikan VO. 2006. "Alcohol beverage type, problem drinking and self-reported health status," Nig. J. Psych. 4: $4-8$.

18. Hiruma -Lima C, Calvo T, Rodrigues C, Andrabe F, Vilegas W, Brito A. 2006. Antiulcerogenic activity of Alchorneacastaneaefolia: Effects on somatostatin, gastrin and prostaglandin. J. Ethnopharm. 104: 215224.

19. Ijarotimi O, Soyoye DO, Adekanle O, Ndububa DA, Umoru BI, Alatise OI. 2017. Declining prevalence of duodenal ulcer at endoscopy in Ile-Ife, Nigeria. South Afr. Med. J. 107:750-753.

20. Jainu M, Devi CSS, 2006.Antiulerogenic and ulcer healing effects of Solanum nigrum (L.) on experimental ulcer models: Possible mechanism for the inhibition of acid formation, J. Eth. 104: 156-163.

21. Lasebikan V, Baiyewu O. 2009. "Profile of problems associated with psychoactive substance use among long distance commercial automobile drivers in Ibadan. Nig. J. Psych. 7:7-16.

22. Lasebikan VO and Ayinde OO. 2013. "Rapid situation assessments of alcohol and substance use among commercial drivers in Nigeria. East Afr. Med. J. 89: 363-371.

23. Baldioli M, Servili G, Perretti GF, Montedoro G F. 1996. J. Amr. Oil Chem. Soc. 73: 1589-1593.

24. Majumdar MN, Nayeem JV, Kamath J, Asad M. 2007. Evaluation of Tectona grandis leaves for wound healing activity, Pak. J. Pharm. Sci. 20: 120-124.

25. Mizuno $\mathrm{H}$, Sakamoto $\mathrm{CH}$, Matsuda K. 1997. Introduction of cyclooxygenase 2 in gastric mucosal lesions and its inhibition by specific antagonist delays healing in mice, J. Gastroenterol. 12:387-397.

26. Moshage H, Kok B, Huizenga JR, Jansen PL. 1995. Nitrite and nitrate determinations in plasma: a critical evaluation. Clin. Chem. 41: 892-896.

27. Mozafar K and Hossein S. 2006. Protective Effect of Falcaria vulgaris Extract on Ethanol Induced Gastric Ulcer in Rat, Iran J. Pharm. Ther. 5: 43-46.

28. Nakamura $Y$ and Miyoshi N. 2010. Electrophiles in foods, the current status of isothiocyanates and their chemical biology, J. Biosci. Biotech. Biochem. 74: 242-255.

29. Narataruksa P, Pichitvittayakarn W, Heggs PJ, Tia S. 2010. Fouling behavior of coconut milk at pasteurization temperatures J. Appl. Therm. Engr..30:1387-1395.

30. Nneli R and Woyike OA. 2008. Antiulcerogenic effects of coconut (Cocos nucifera) extract in rats, Phytother Res. 22: 970-972.

31. Oh TY, Ahn GJ, Choi SM, Ahn BO, Kim WB. 2005. Increased susceptibility of ethanol-treated gastric mucosa to naproxen and its inhibition by DA-9601, an Artemisia asiatica extract, World J. Gastroent. 11:7450-7456. 
32. Okokon JE, Umoh UF, Udobang JA, Etim EI, Antiulcerogenic Activity of ethanolic Leaf Extract of Croton zambesicus Muell. Arg. Afr. J. Biomed. Resour. 14 (2011) 43-47.

33. Oyedapo OO, Sab FC, Olagunju JA. 1999. Bioactivity of fresh leaves of Lantana camara. J. Biomed. Lett. 59:175-183.

34. Peskar BM, Gunter B, Peskar BA. 1980. Prostaglandins and prostaglandin metabolites in human gastric juice. Prostaglandins. 20:419-427.

35. Rydning A, Berstad A, Aadland E, Odegaard R. 1982. Prophylactic effect of dietary fiber in duodenal Ulcer disease, Lancet. 2: 736-739.

36. Taye A and Saad AH. 2009. Role of rosiglitazone as a gastro protective agent against indomethacininduced gastric mucosal injury in rats, Gastroent. Res. 2:324-332.

37. Udegbunam SO, Udegbunam RI, Nnaji TO, Anyanwu MU, Chukwujekwu Kene RO, Anika SM. 2015. Antimicrobial and antioxidant effect of methanolic Crinum jagus bulb extract in wound healing, 4: 239248.

38. Voutilainen M, Mantynen T, Farkkila M, Juhola M, Syponene P. 2001. Impact of non-steroidal antiinflammatory Drug and aspirin use on the prevalence of dyspepsia and uncomplicated peptic ulcer. J. Gastroenterol. 36: 817-821.

39. World Health Organization, Global Status Report on Alcohol (2004), In: Webcite,11.11.2010, Available from http://www.who.int/substance_abuse/publications/global_status_report_2004_overview.pdf. Retrieved on 04-06-2018. 